\title{
Kinesiologic Study of Shoulder Joints and Acromioclavicular Joint in Women Undergoing Unilateral Breast Surgery of the Type Mastectomy and Quadrantectomy
}

Antonia Bankoff*

Faculty of Physical Education, Department of Sport Science, State University of Campinas, Sao Paulo Brazil

\begin{abstract}
This study includes 20 women studied by simple goniometry with mean age 57.7 years, being 09 with unilateral quadrantectomy type surgery, 01 with bilateral quadrantectomy type surgery and 10 with unilateral mastectomy surgery. The mean operative time was 9.8 (nine years and eight months). The degrees range of motion in the shoulder joints (surgical and nonsurgical side) was performed using Goniometer FisioStore. For the statistical analysis we used analysis of variance (ANOVA) double-factor without repetition $(p<0.05)$ comparing the types of surgery and the operated and non-operated sides. The results showed significant difference $(p<0.05)$ between the operated and non-operated side for both joints studied and all studied movements. There was no significant difference in range of joint motion between the types of surgery (mastectomy and quadrantectomy). On the operated side the difference was always above 20 degrees. In the case of bending motion of the arm the difference between operated and nonoperated reached 40 degrees.
\end{abstract}

Keywords: Kinesiology; Range of motion; Breast Surgery; Goniometry

\section{Introduction}

The shoulder joint, formed by the articulation of the humerus with the scapula, is the most mobile of all the joints formed by a head and a cavity. The glenoid cavity, shallow, is marked by a layer of the glenoid labrum cartilage placed firmly on the inner surface of the cavity and the head of the humerus fits into this pit. The joint is surrounded, as we know, by the capsular ligament which is strengthened in front by a resistant band of fibers that connect the humerus to the coracoid process and it is known as coracoumeral ligament [1].

The acromioclavicular joint is a fully mobile sliding synovial joint. Anteriorly, it is reinforced by the acromioclavicular ligament, a joint capsule thickening. The main element of protection of the joint from injury is the coracoclavicular ligament, composed of two strong fibrous bands, the conoid and trapezoid ligaments, which attach to the top of the coracoid process with the inferior surface of the clavicle [1].

As a result of the treatment of breast cancer, several complications have been reported, among them, those resulting from surgery. Among the surgical techniques that can be performed, the mastectomy or conservative surgery, which may be associated with axillary lymphadenectomy (AL) or sentinel lymph node biopsy [2]. Among the surgical complications of AL found, there is the long thoracic nerve injury [3]. Most injuries of this nerve are partial and transient (neuropraxia), which gradually recovers with conservative treatment [2]. However, when this regression does not occur in the first six months, the lesion can be considered complete, with few chances of rehabilitation [4].

After mastectomy and excision of adjacent lymph nodes, the patient may present some complications such as pain, lymphedema in the upper limb involved and the chest wall adhesions, which can result in increased risk of postoperative pulmonary complications, decreased range of motion (DRM) of the shoulder on the affected side and postural deformity of the trunk [5].

As stated by Assunção et al. [6] the upper limb lymphedema after mastectomy entails numerous consequences such as decreased muscle strength and range of motion of joints involved, in addition to triggering complaints of muscle tension, pain and increased weight of the upper limb affected. These changes associated with chronicity of the process of post mastectomy lymphedema, means that there is great potential for developing postural asymmetries.

Corroborating with the above-mentioned authors, Sasaki and Lamari et al. [7] state that the shoulder is the joint most commonly affected due to the limited mobility in the upper limb homolateral to the breast surgery.

The long thoracic nerve injury results in decreased strength or paralysis of the serratus anterior muscle, leading to destabilization of the scapular girdle with prominence of the medial border of the scapula and rotation of the inferior angle on the middle line, featuring a winged scapula [8]. In addition to the specific lesion of the long thoracic nerve, muscle changes are also observed, as the morbidity related to muscles in the shoulder joint and scapular stabilization, citing, in addition to the serratus anterior muscle, others as, for example, the upper trapezius and medium deltoid [9].

After the AL in the treatment of breast cancer, the prevalence of winged scapula has varied from 1.5 to $12.6 \%$ [10] and the incidence of 8 to $30 \%$ [11]. In a cross-sectional study conducted in Rio de Janeiro, was observed prevalence of $6.3 \%$ in women with seven to 287 months elapsed after the AL. In an incidence study in 599 women who underwent AL, we observed the presence of winged scapula in $69.5 \%$ of the patients evaluated in the immediate postoperative period [12].

The efficacy of physiotherapists as well as the recovery of normal

*Corresponding author: Antonia bankoff, Faculty of Physical Education Department of Sport Science, State University of Campinas, Sao Paulo, Brazil, E-mail: bankoff@fef.unicamp.br

Received January 18, 2012; Accepted February 11, 2012; Published February 11, 2012

Citation: Bankoff A (2012) Kinesiologic Study of Shoulder Joints and Acromioclavicular Joint in Women Undergoing Unilateral Breast Surgery of the Type Mastectomy and Quadrantectomy. Surgery 2:110. doi:10.4172/21611076.1000110

Copyright: $\odot 2012$ Bankoff A, et al. This is an open-access article distributed under the terms of the Creative Commons Attribution License, which permits unrestricted use, distribution, and reproduction in any medium, provided the original author and source are credited. 
movement in cases of neuropraxia may be accompanied by physical examination.

\section{Decreased Shoulder Range of Motion}

Range of motion (ROM) is the complete possible motion of a segment, being maintained by periodic movement of the member. Some factors may lead to impairment of ROM. Among them we emphasize the surgical aggression and inactivity or immobilization of the limb. In case of realization of radical mastectomy, the major and minor pectoralis are removed, resulting in decrease in strength and changing the function of the upper limb involved [13]. The same occurs when the nerve of Bell is temporarily traumatized during axillary dissection, resulting in weakness of the serratus anterior muscle, disrupting movement of the scapula and shoulder abduction on the affected side $[14,15]$. The rehabilitation of the scapular girdle of the upper limb is a basic need in the patient undergoing surgery for breast cancer, whatever the surgical technique employed. Its main objective is to restore as soon as possible limb function [16].

Baraúna et al. [17] studied the range of shoulder movement in mastectomized women by Computerized Biophotogrammetry in 29 mastectomized women aged between 33 and 80 years, 6 months or more of postoperative. According to the results, we found significant differences for the flexion movements of the shoulder homolateral to the mastectomy when compared with the contralateral side. We verified a significant decline in the flexion movement of the shoulder homolateral to the mastectomy.

\section{Material and Methods}

It was studied by Goniometry the range of motion of the shoulder joint. The acromioclavicular joint was measured displacement of the scapula in the movement of rising and lowering of the shoulder, measured in $\mathrm{cm}$ using a measuring tape, in order to verify the possible differences between surgical and nonsurgical side and the difference between types of surgery (mastectomy and quadrantectomy).

\section{Population}

The sample comprised 20 women with mean age 57.7 years old, being 09 with unilateral quadrantectomy type surgery, 01 with bilateral quadrantectomy type surgery and 10 with unilateral radical mastectomy surgery, belonging to the REVIVER NGO in the city of Americana-São Paulo. The mean operative time was 9.8 (nine years and eight months). The study was conducted with women who underwent this surgery over a period of six months and performed all physical therapy after surgery recommended by the doctor and by the SUS (Sistema Unico de Saúde) being 12 sessions after surgery. The woman with bilateral quadrantectomy surgery was considered in the surgical group both sides.

\section{Instruments, procedures and data collection}

The range of motion of the shoulder joint was measured using a goniometer FisioStore. In the acromioclavicular joint it was measured the displacement of the scapula in the movement of raising and lowering the shoulders measured in $\mathrm{cm}$ using a measuring tape from the inferior angle of the scapula. The experimental part was held at the Headquarters where the Grupo Reviver meets weekly in the city of Americana-SP.

All the subjects in the study were wearing only a bra avoiding interference in the measurements during the performance of joint movements.
The study was conducted by the Laboratory of Electromyography and Biomechanics of Posture, School of Physical Education - Unicamp. For each procedure before starting data collection, the subject was asked three times to conduct the activities of the sequential movements of the shoulder joint, thus avoiding some sort of error during execution.

All subjects in the study signed a consent form for participation in the research. The project was approved by the Ethics Committee of Unicamp according to No. 984/2010. The movements studied were: flexion and hyperextension of the arm, arm abduction and adduction, horizontal flexion and extension of the arm, internal and external rotation of the arm, shoulder elevation and lowering measuring the displacement of the scapula from the inferior angle of the latter.

\section{Results}

The results shown in figures 1 and 2 were grouped considering the two types of surgery (mastectomy and quadrantectomy) from the right or left surgical side.

The figure 1 shows the right side of surgery in 11 women, and figure 2 shows the left side of surgery in 09 women. We noted that the figures provided by the surgical side are always lower in range of motion when compared with the non-surgical side. There is little difference in range of motion between the right and left surgical sides if you look at the surgical sequence of movements performed. As for example, the movement of flexion of the arm on the surgical side and range of motion remained around 90 degrees which greatly limits the performance of daily tasks. In the adduction movement amplitude remained at $60^{\circ}$, i.e., they cannot bring the arm of the body altogether. The abduction remained at $80^{\circ}$ when the ideal is $90^{\circ}$ or above this value. The flexion and horizontal extension starting with the arm flexed position to $90^{\circ}$, range of motion was less than $20^{\circ}$, i.e., they are movements we use in our everyday lives in everyday tasks and on the surgical side they lost averaged over $10^{\circ}$ range of motion. In the movements of internal and external rotation, the range of $40^{\circ}$ recorded can be considered good

Mean and standard deviation - the right surgery. $\mathrm{N}=11$

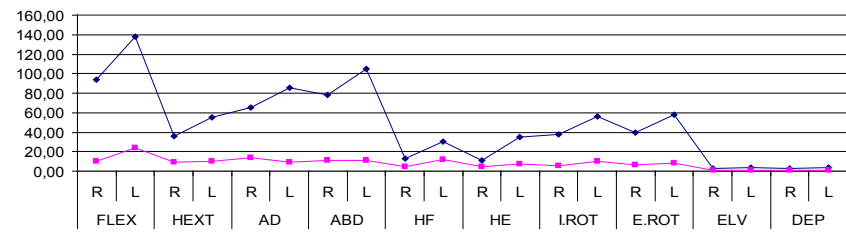

Figure 1: General Mean and standard deviation regarding the range of motion of the shoulder joint collected from 11 women undergoing breast surgery of the types unilateral mastectomy and quadrantectomy (right surgical side).

Mean and standard deviation - left surgery $\mathrm{N}=\mathbf{9}$

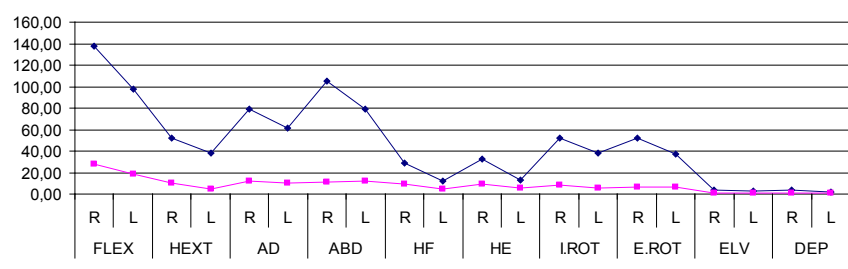

Figure 2: General Mean and standard deviation regarding the range of motion of the shoulder joint collected from 09 women undergoing breast surgery of the types quadrantectomy and unilateral mastectomy (left surgical side). 
range. In lifting and lowering movements of the shoulder by the scale of the graph one cannot see, however, it always showed a difference in average from 1.5 to $2.0 \mathrm{~cm}$ between the surgical and nonsurgical side. For example: The non-surgical side of the shoulder showed an increase of $4.0 \mathrm{~cm}$, while the surgical side showed $2.0 \mathrm{~cm}$.

Therefore, the results in the figures 1 and 2 show that the surgical side, regardless of whether the right or left side there is a significant loss of range of motion of the shoulder joint movements performed by it. We found a difference of $40^{\circ}$ less range of motion on the surgical side compared with the nonsurgical side. The results for the range of motion of the shoulder and acromioclavicular joints measured in degrees were statistically analyzed by analysis of variance two-factor ANOVA without repetition where $\mathrm{p}<0.05$. The results were significant when comparing surgical and nonsurgical side regardless of being right or left in all the movements studied. When compared between the types of surgery (mastectomy and quadrantectomy) the results were not significant for the movements studied, i.e., both surgeries cause a decrease in relation to the range of movements and serious consequences for women.

To better understand the results of the Analysis of VarianceANOVA double-factor without repetition where $\mathrm{p}<0.005$ are distributed and displayed in the figures 3, 4, 5, 6 and 7.

\section{Discussion}

The loss of range of motion seems to be related to the thoracic nerve injury and also with the lack of physical therapy, lymphatic drainage and rehabilitation exercise therapy applied. Some authors cited in this study reported that among the surgical complications of $\mathrm{AL}$, we can observe the long thoracic nerve injury [3]. Most injuries of this nerve are partial and transient (neuropraxia), which gradually recovers with conservative treatment [2]. However, when this regression does not occur in the first six months, the lesion can be considered complete, with few chances of rehabilitation [4].

When we started the project for some reason I thought it would be something very easy to accomplish, however, when it became reality I realized it was something bigger than I thought, because it would be

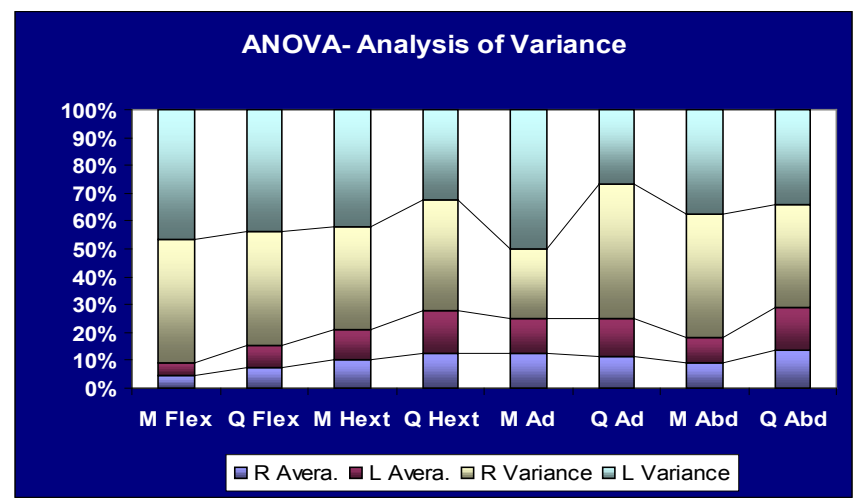

The lowest values for the bending motion of the arm specifically the subjects with mastectomy surgery. It is visible the compromise of the joints studied in these types of surgery for the results presented

Figure 3: Results of analysis of variance - ANOVA, double-factor without repetition of range of motion of the shoulder joint by comparing the types of surgery: mastectomy and quadrantectomy. Following the order by column we can see: right side mean, left side mean, right side variance and left side variance, respectively.

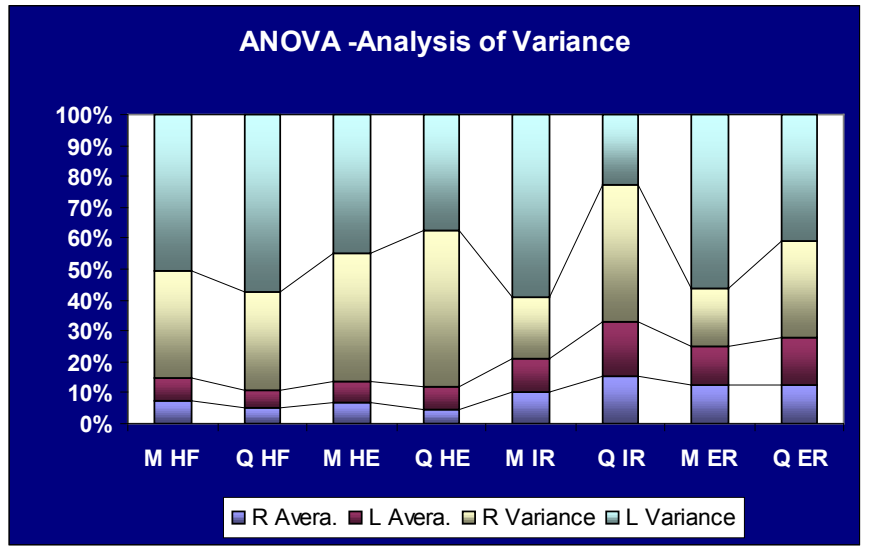

We can see how the movements of flexion and horizontal extension are compromised, specifically of the type quadrantectomy

Figure 4: Results of Analysis of Variance - ANOVA double-factor without repetition of range of motion of the shoulder joint by comparing the types of surgery: mastectomy and quadrantectomy. Following the order by column we can see: right side mean, left side mean, right side variance and left side variance, respectively.

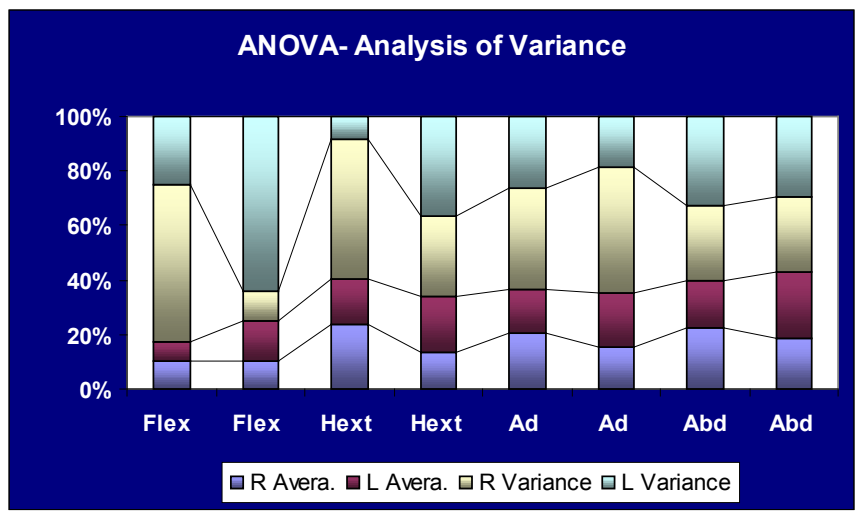

Figure 5: Results of Analysis of Variance - ANOVA double-factor without repetition of range of motion of the shoulder joint right and left sides (surgical and nonsurgical), not considering the types of surgery. Following the order by column we can see: right side mean, left side mean, right side variance and left side variance, respectively.

somehow playing on people's emotional aspect and that is exactly what happened, each woman told her story and assessed her problems as a result of surgery and her quality of life before and after surgery. So it was not just an evaluation assessment, there were many assessments and listening to every woman involved in the research. In fact, my work is one of the most significant in the last five years of my academic career. When I discussed the project and drafted the literature, i was impressed by the statements of some authors affirming that the recovery was long overdue. The long thoracic nerve injury results in decreased strength or paralysis of the serratus anterior muscle, leading to destabilization of the shoulder girdle on the prominence of the medial border of the scapula and inferior angle of rotation of the middle line, featuring a winged scapula [8]. In our assessment the serratus anterior muscle was the muscle that showed the lowest values of action potentials when transformed in RMS, exactly as described by Schmitz et al. [8]. Given the values of range of motion of the shoulder joint the most outstanding was the loss of flexion range of motion around $40^{\circ}$ of the surgical side and in the movements of extension and horizontal flexion 
Citation: Bankoff A (2012) Kinesiologic Study of Shoulder Joints and Acromioclavicular Joint in Women Undergoing Unilateral Breast Surgery of the Type Mastectomy and Quadrantectomy. Surgery 2:110. doi:10.4172/2161-1076.1000110

Page 4 of 5

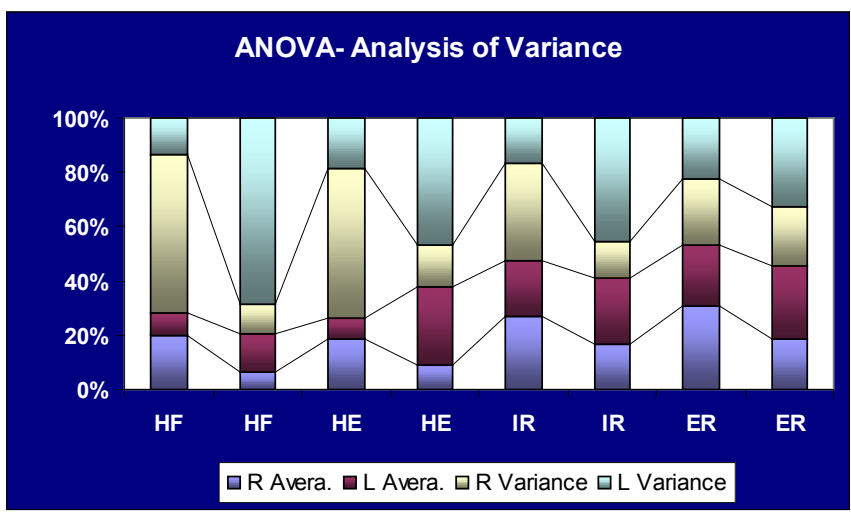

Figure 6: Results of Analysis of Variance - ANOVA double-factor without repetition of range of motion of the shoulder joint right and left sides (surgical and nonsurgical), not considering the types of surgery. Following the order by column we can see: right side mean, left side mean, right side variance and left side variance, respectively.

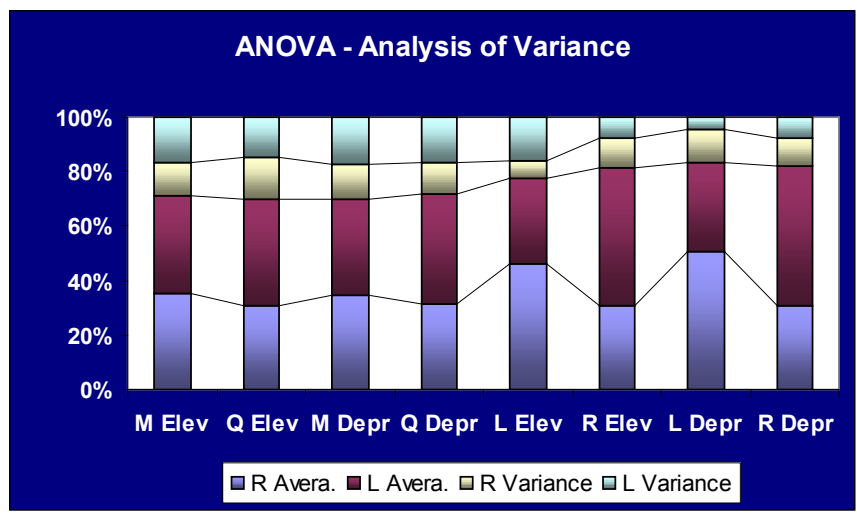

Figure 7: Results of analysis of variance - ANOVA double-factor without repetition of range of motion of lifting and lowering the shoulder blade by measuring the displacement of comparing types of surgery (mastectomy and quadrantectomy) and right and left surgical and nonsurgical sides. Following the order by column we can see: right side mean, left side mean, right side variance and left side variance, respectively.

on the surgical side of the arm. Many patients indicated that they cannot dance in "couple" if it requires to place an arm in horizontal extension and abduction, especially if is the surgical side arm, because they claim a feeling of "pulling" and they cannot dance in this posture. Shamley et al. [9] describes that in addition to the specific lesion of the long thoracic nerve, muscle changes are also observed, as the morbidity related to muscles in the shoulder joint and scapular stabilization, and also cites, in addition to the serratus anterior muscle, others such as the upper trapezius and middle deltoid. Campbell [4] reports that when this regression does not occur in the first six months, the lesion can be considered complete, with few chances of rehabilitation.

Checking the results one can conclude that the majority of daily tasks using these movements of the shoulder joint they are committed with the need for implementation of physical therapy exercises to gain range of motion and improving the quality of life of women affected by this type of surgery, noting that in most of the daily tasks these movements are required.

In conversation with these women and also in the questionnaire answered by them, the biggest complaint is the same loss of range of motion of the shoulder joint and consequently the difficulties of performing the tasks of everyday's life.

\section{Conclusion}

Based on the results we believe we can draw the following conclusions:

- There is urgent need for the State to review the issues of rehabilitation and quality of life of women affected by these types of surgeries.

- We felt that only a dozen physical therapy sessions with little contributed to shoulder and acromioclavicular joint in relation to range of motion performed by them.

- The operated side, regardless of the type of surgery lost an average of 20 degrees range of motion of the shoulder joint. In the bending motion of the arm the average was around 40 degrees.

- The operated side, regardless of the type of surgery lost an average of $2.0 \mathrm{~cm}$ range of motion of lifting and lowering the shoulder and acromioclavicular.

- There were significant differences between operated and nonoperated side $(\mathrm{p}<0.05)$ for the muscles studied.

- There was no significant difference between the types of surgery (mastectomy and quadrantectomy).

\section{References}

1. Dalla P (2007) Morfologia e Cinesiologia Aplicada ao Movimento Humano Guanabara Koogan.

2. Langer I, Guller U, Berclaz G, Koechli OR, Schaer G, et al. (2007) Morbidity of sentinel lymph node biopsy (SLN) alone versus SLN and completion axillary lymph node dissection after breast cancer surgery: a prospective Swiss multicenter study on 659 patients. Ann Surg 245: 452-461.

3. Freitas-Júnior R, Ribeiro LFJ, Taia L, Kajita D, Fernandes MV, et al. (2001) Linfedema em pacientes submetidas à mastectomia radical modificada. Rev Bras Ginecol Obstet 23.

4. Campbell WW (2008) Evaluation and management of peripheral nerve injury Clin Neurophysiol 119: 1951-1965.

5. Kistner RW (1989) Ginecologia: Princípios e prática (4a edn) São Paulo, Manole.

6. Assunção MLAC, Mello NM (1990) Prevenção de linfedema pós mastectomia radical. Fisioter Mov 3: 59-79.

7. Sasaki T, Lamari NM (1997) Reabilitação funcional precoce pós mastectomia HB Cient 4: 121-127.

8. Schmitz C, Sodian R, Witt TN, Juchem G, Lang N, et al. (2009) Winged scapula after aortic valve replacement. Ann Thorac Surg 87: 1277-1279.

9. Shamley DR, Srinanaganathan R, Weatherall R, Oskrochi R, Watson M, et al (2007) Changes in shoulder muscle size and activity following treatment for breast cancer. Breast Cancer Res Treat 106: 19-27.

10. Sahin F, Yilmaz F, Esit N, Aysal F, Kuran B (2007) Compressive neuropathy of long thoracic nerve and accessory nerve secondary to heavy load bearing. A case report. Eura Medicophys 43: 71-74.

11. Paim CR, de Paula Lima ED, Fu MR, de Paula Lima A, Cassali GD (2008) Post lymphadenectomy complications and quality of life among breast cancer patients in Brazil. Cancer Nurs 31: 302-309.

12. Bergmann A, Mattos IE, Koifman RJ, Ribeiro MJP, Nogueira EA, et al. (2005) Incidência de complicações no pós-operatório imediato: análise descritiva de 599 mulheres submetidas a linfadenectomia axilar no câncer de mama. In: $13^{\circ}$ Congresso Brasileiro de Mastologia, Rio de Janeiro, Brasil.

13. Kisner C, Colby LA (1998) Exercícios terapêuticos: fundamentos e técnicas. São Paulo, Manole. 
Citation: Bankoff A (2012) Kinesiologic Study of Shoulder Joints and Acromioclavicular Joint in Women Undergoing Unilateral Breast Surgery of the Type Mastectomy and Quadrantectomy. Surgery 2:110. doi:10.4172/2161-1076.1000110

Page 5 of 5

14. Box RC, Reul-Hirche HM, Bullock-Saxton JE, Furnival CM (2002) Physiotherapy after breast cancer surgery: results of a randomised controlled study to minimise lymphoedema. Breast Cancer Res Treat 75: 51-64.

15. Camargo MC, Marx AG (2000) Reabilitação física no câncer de mama. Roca, São Paulo.
16. Nagel PH, Bruggink ED, Wobbes T, Strobbe LJ (2003) Arm morbidity after complete axillary lymph node dissection for breast cancer. Acta Chir Belg 103: 212-216.

17. Baraúna MA, Canto RST, Schulz E, da Silva RAV, Silva CDC, et al. (2004) Shoulder movement range assessment in mastectomized women through computerized biophotogrammetry. Revista Brasileira de Cancerologia 50: 2731. 